\title{
SIGNIFICANCE OF CLINICAL AND HISTOPATHOLOGICAL EVALUATION IN WOMEN WITH POSTMENOPAUSAL BLEEDING
}

\author{
Khajuria Reema1, Dinesh Kumar'2, Surinder Kumar³, Shivali Sharma4, Saba Musharraf ${ }^{5}$ \\ ${ }^{1}$ Lecturer, Department of Obstetrics and Gynaecology, SMGSH, GMC, Jammu. \\ ${ }^{2}$ Senior Resident, Department of Obstetrics and Gynaecology, SMGSH, GMC, Jammu. \\ 3Professor, Department of Obstetrics and Gynaecology, SMGSH, GMC, Jammu. \\ 4Junior Resident, Department of Obstetrics and Gynaecology, SMGSH, GMC, Jammu. \\ 5Junior Resident, Department of Obstetrics and Gynaecology, SMGSH, GMC, Jammu.
}

\begin{tabular}{l}
\hline ABSTRACT \\
BACKGROUND \\
Postmenopausal bleeding is generally regarded as an ominous and serious alarm of genital pathology. The aim of the present \\
study was to investigate the clinical significance and endometrial pathology in patients with postmenopausal bleeding.
\end{tabular}

\section{MATERIALS AND METHODS}

This retrospective study was conducted in the Postgraduate Department of Obstetrics and Gynaecology, SMGS Hospital, Jammu over a period of one year in which 60 cases of postmenopausal bleeding were enrolled in the study. All patients were subjected to detailed history, examination and investigations followed by diagnostic curettage.

\section{RESULTS}

Majority of the patients with postmenopausal bleeding were in the age group of 55 (53.35\%), majority of cases 37 (61.67\%) were para 4-6. Mean age of onset of menopause was 48.8 years. Obesity was found in 25 cases (41.67\%), hypertension in 23 cases (38.33\%) and diabetes in 10 cases (16.67\%). Out of the 60 cases studied, the most common cause of post-menopausal bleeding was atrophic endometrium 25 cases (45\%) followed by endometrial hyperplasia 17 cases (38.33\%). Endometrial polyps were found in 5 cases (15\%), endometrial adenocarcinoma was found in 9 cases (15\%).

\section{CONCLUSION}

From our study, it was observed that the most common cause of postmenopausal bleeding was atrophic endometrium followed by endometrial hyperplasia. Medical illnesses were found more frequent in patients with atypical hyperplasia and endometrial adenocarcinoma as risk factors.

\section{KEYWORDS}

Postmenopausal Bleeding, Diagnostic Curettage, Endometrial Hyperplasia, Endometrial Adenocarcinoma, Atrophic Endometrium.

HOW TO CITE THIS ARTICLE: Reema K, Kumar D, Kumar S, et al. Significance of clinical and histopathological evaluation in women with postmenopausal bleeding. J. Evolution Med. Dent. Sci. 2016;5(82):6129-6132, DOI: 10.14260/jemds/2016/1384

\section{BACKGROUND \\ Postmenopausal bleeding accounts for $5 \%$ of office gynaecology presentations. ${ }^{1}$ It is defined as any bleeding from the genital tract occurring in the postmenopausal period arising after 12 months amenorrhoea in a woman of menopausal age. ${ }^{2}$ The average age of menopause in Asian women is 46 years. ${ }^{3}$ A woman not taking hormone replacement therapy who bleeds after the menopause has a $10 \%$ risk of having genital cancer and a further $10 \%$ risk of significant pathology.4 Therefore, postmenopausal bleeding should always be investigated no matter how minimal or persistent. While the most common cause for postmenopausal bleeding is atrophy, the diagnostic algorithm for}

Financial or Other, Competing Interest: None.

Submission 30-08-2016, Peer Review 30-09-2016,

Acceptance 06-10-2016, Published 12-10-2016.

Corresponding Author:

Dr. Reema Khajuria,

House No. 18

Opp. JRC Home Udhaywala,

Bohri, Jalab Hills, Talabtilla, Jammu - 180002.

E-mail:drreema2014@gmail.com

DOI: $10.14260 /$ jemds/2016/1384 postmenopausal bleeding is designed to detect cancer, particularly endometrial cancer. ${ }^{1}$ Atrophy accounts for 60 to $80 \%$ of all causes of post-menopausal bleeding, while endometrial hyperplasia and cancer each accounts for $10 \%$ of cases. 1,5

The remaining causes are attributed to endometrial or cervical polyps (2 to $12 \%$ ); exogenous oestrogen (15 to $25 \%$ ); cervical cancer (1\%) and factors such as vaginal trauma, anticoagulants and bleeding from non-gynaecological sites.1,5

Like any other presentation in gynaecology, the evaluation of post-menopausal bleeding starts with a thorough history and physical examination. Transvaginal ultrasound (TVUS) is considered an acceptable initial investigation in woman with post-menopausal bleeding. 1,6 Endometrial thickness $<5 \mathrm{~mm}$ on TVUS usually excludes endometrial cancer; however, solitary use of ultrasound is not recommended in the exclusion of cancer. ${ }^{7}$ An endometrial biopsy is considered the gold standard for evaluation of post-menopausal bleeding.5,7 Endometrial biopsy can be obtained with an endometrial pipelle or by hysteroscopy and curettage. ${ }^{7}$

The clinical evaluation and endometrial curettage is a better option of diagnosis, especially in our low resource setup where the diagnostic facilities are not available to all the patients. This study was aimed to present a hospital-based 
survey to investigate the clinical significance of postmenopausal bleeding in terms of aetiology, risk factors, incidence of malignancy and histopathological evaluation.

\section{MATERIALS AND METHODS}

This retrospective study was conducted in the postgraduate Department of Obstetrics and Gynaecology, SMGS Hospital, Jammu, over a period of one year in which 60 cases of postmenopausal bleeding with endometrial origin were enrolled in the study. Other causes of postmenopausal bleeding were excluded from the study like vulval, vaginal, cervical, endocrine and systemic causes. Patients on anticoagulants or hormones were also excluded from the study.

All patients were subjected to detailed history of symptoms, menstrual history, duration of menopause, interval between menopause and present bleeding, menstrual pattern prior to menopause and thorough general physical, systemic and local examination including per speculum and bimanual examination. Investigations including complete blood picture, blood sugar, transabdominal and transvaginal ultrasound were done. After selection of patients were subjected to diagnostic curettage under general anaesthesia, specimens were collected and sent for histopathological examination in $10 \%$ formalin. Hysteroscopy could not be done (Though a significant diagnostic aid and done in many comparative studies) due to departmental constraints.

\section{RESULTS}

This retrospective study evaluated 60 patients of postmenopausal bleeding. Most of the patients, i.e. 32 were between 55-65 years (53.35\%) followed by 22 (36.67\%) between $45-55$ years and $6(10 \%)$ between $65-75$ years. Mean age of onset of menopause was 48.8 years with majority of women having onset of menopause in the age range of 46-50 years (62\%). Majority of cases $37(61.67 \%)$ were para 4-6; 14 (23.33\%) were para $1-3$; $8(13.33 \%)$ were para $>6$ and one nulliparous patient.

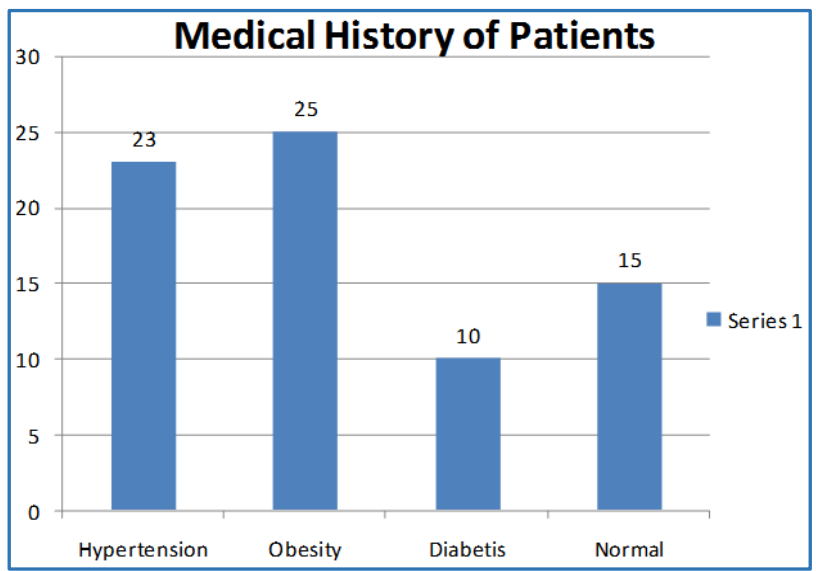

Obesity was found in 25 cases (41.67\%), hypertension in 23 women $(28.33 \%)$ and diabetes in 10 cases $(16.67 \%)$.

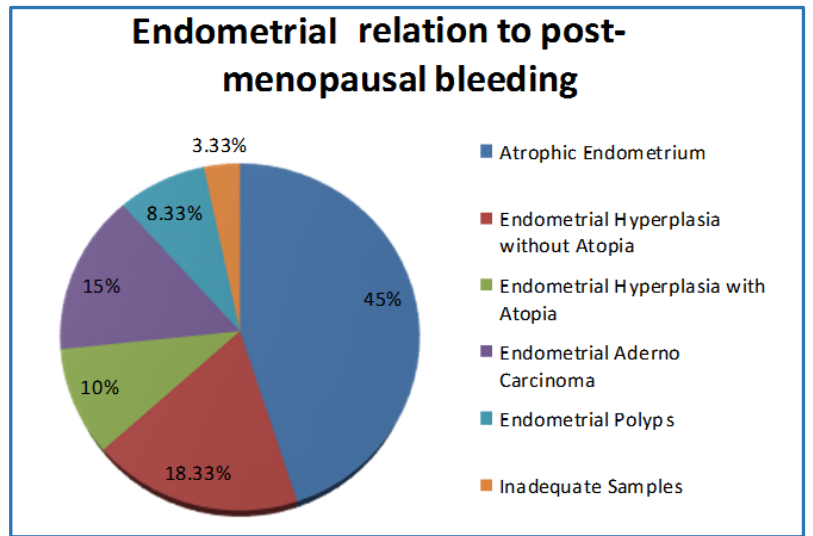

Out of 60 cases studied, the most common cause of bleeding in the postmenopausal age group women was atrophic endometrium $27(45 \%)$ cases, endometrial hyperplasia without atypia $11(18.33 \%)$ cases, endometrial hyperplasia with atypia $6(10 \%)$ cases, endometrial carcinoma in $9(15 \%)$ cases, endometrial polyps in $5(8.33 \%)$ cases and in $2(3.33 \%)$ cases samples were found inadequate.

Types of endometrial hyperplasia are shown in Table No. 1.

\begin{tabular}{|c|c|c|}
\hline Type of Hyperplasia & No. of Cases & Percentage \\
\hline \multicolumn{3}{|l|}{ (i) Simple hyperplasia } \\
\hline (a) Without atypia & 8 & 47.06 \\
\hline (b) With atypia & 4 & 23.53 \\
\hline \multicolumn{3}{|l|}{ (ii) Complex hyperplasia } \\
\hline (a) Without atypia & 3 & 17.65 \\
\hline (b) With atypia & 2 & 11.76 \\
\hline Total & 17 & 100 \\
\hline \multicolumn{3}{|c|}{ Table 1: Types of Hyperplasia } \\
\hline
\end{tabular}

Age of patients ranged from 45 years to 75 years. In the age group of 45 to 55 years, the commonest endometrial lesion was found to be endometrial hyperplasia 10 cases followed by atrophic endometrium 8 cases, endometrial polyps 3 cases, endometrial adenocarcinoma 2 cases and one sample was found inadequate. In the age group of 56 to 65 years, the commonest endometrial lesion was found to be atrophic endometrium 16 cases, endometrial hyperplasia 6 cases, endometrial adenocarcinoma 5 cases, endometrial polyps 2 cases and one sample was found inadequate. In the age group of 66 to 75 years the commonest endometrial lesion was found to be atrophic endometrium 3 cases, endometrial adenocarcinoma 2 cases and one case of endometrial hyperplasia.

Relationship of age with different endometrial lesions is shown in Table No. 2.

\begin{tabular}{|c|c|c|c|}
\hline $\begin{array}{c}\text { Endometrial } \\
\text { Histopathology }\end{array}$ & $\begin{array}{c}\text { Age } \\
\text { (45-55) }\end{array}$ & $\begin{array}{c}\text { Age } \\
\text { (56-65) }\end{array}$ & $\begin{array}{c}\text { Age } \\
\text { (66-75) }\end{array}$ \\
\hline Atrophic Endometrium & 8 & 16 & 3 \\
\hline $\begin{array}{c}\text { Endometrial Hyperplasia } \\
\text { without atypia }\end{array}$ & 7 & 4 & 0 \\
\hline $\begin{array}{c}\text { Endometrial Hyperplasia } \\
\text { with atypia }\end{array}$ & 3 & 2 & 1 \\
\hline $\begin{array}{c}\text { Endometrial } \\
\text { adenocarcinoma }\end{array}$ & 2 & 5 & 2 \\
\hline Endometrial Polyps & 3 & 2 & 0 \\
\hline Inadequate samples & 1 & 1 & 0 \\
\hline Total & $\mathbf{2 2}$ & $\mathbf{3 2}$ & $\mathbf{6}$ \\
\hline Table 2: Relationship of Age with Different \\
Endometrial Lesions \\
\hline \multicolumn{4}{|c|}{}
\end{tabular}


In our study, the duration of menopause ranged from 1 year to maximum 20 years. In the span of 1 to 5 years 8 cases were diagnosed as endometrial hyperplasia, 6 cases were having atrophic endometrium, 1 case of endometrial polyp and 2 cases of endometrial carcinoma. In the span of 6 to 10 years 10 cases were having atrophic endometrium, 6 cases were diagnosed as endometrial hyperplasia, 2 cases of endometrial carcinoma, 2 samples were found inadequate. In the span of 11 to 15 years 8 cases were having atrophic endometrium, 6 cases were diagnosed as endometrial hyperplasia, 2 cases of endometrial carcinoma, 2 samples were found inadequate.

\section{DISCUSSION}

In our study majority of women presenting with postmenopausal bleeding were in the age group of 55 to 65 years, i.e. 53.33 percent which is similar to study by Kothapally $\mathrm{K}$ et $\mathrm{al}^{8}$ with maximum patients in this age group, i.e. 56.6 percent. In our study postmenopausal bleeding was more common within five to ten years of duration of menopause, i.e. 33.33 percent which is similar to study by Breijer MC et al. ${ }^{9}$ In our study there was history of hypertension in 38.33 percent of women, diabetes mellitus in 16.67 percent of women and 41.67 percent of women were obese. Our observation is comparable to studies by Kavitha et al ${ }^{8}$ and Kant RH et al ${ }^{10}$ who found hypertension, diabetes and obesity in 30.6 percent, 13.3 percent, 43.3 percent and 30.2 percent, 10.3 percent, 34.5 percent respectively. In our study atrophic endometrium was the most common histological diagnosis, i.e. in 27 (45\% cases). Dangal $\mathrm{G}$ et $\mathrm{al}^{11}$ and Kaur $\mathrm{M}$ et al ${ }^{12}$ found atrophic endometrium in maximum number of patients, i.e. 64.4 percent and 53 percent respectively.

There are many theories behind bleeding in atrophic endometrium like sclerotic degeneration of endometrial vessels or local abnormal haemostatic mechanisms in the uterus. Endometrial hyperplasia without atypia was the second most common finding next to atrophic endometrium, i.e. 18.33 percent. This is comparable to study by Karmarkar PJ et $\mathrm{al}^{13}$ who found this in 21.2 percent cases. In other studies, it was found in range from 13.4 percent to 26.6 percent. ${ }^{14,15}$ Endometrial hyperplasia is a condition of the endometrium, which carries both clinical and pathological significance. It is one of the most important predisposing factors for the development of endometrial carcinoma.

This risk is especially seen in atypical endometrial hyperplasia, which carries the risk of associated endometrial carcinoma more than endometrial hyperplasia without atypia. In our study, endometrial hyperplasia with atypia was observed in $10 \%$ cases which is comparable to study by Karmarkar PJ et al ${ }^{13}$ who found it as 7.2 percent. In other studies, it was found in range from 1.8 percent to 8 percent.16,17,18 Endometrial adenocarcinoma which is the most threatened cause of postmenopausal bleeding was found in 15 percent of cases in our study.

In other studies, it was found in range from 6 percent to 12 percent. 16,18.19 Endometrial polyps were found in 8.33 percent cases in our study, which is comparable to study by Kant RH et $\mathrm{al}^{10}$ who found polyps in 7.8 percent of cases. Atrophic endometrium was more frequent in the age group 56 to 65 years, i.e. $59.26 \%$ which is comparable to study by Kant RH et al 10 who found 56.41 percent cases of atrophic endometrium in the age group of 56-65 years.
Endometrial hyperplasia (with or without hyperplasia) was more frequent in age group of 45 to 55 years, i.e. 58.82 percent which is comparable to studies by Kant RH et al ${ }^{10}$ and Naik VS et al. ${ }^{14}$ Endometrial adenocarcinoma was more frequent in the age group of 56 to 65 years in the present study, i.e. 55.55 percent which is similar to studies by Kant $\mathrm{RH}$ et al ${ }^{10}$ and Naik VS et al.14 In the duration of menopause of 1 to 5 years the present study had the highest incidence of endometrial hyperplasia, which is similar to study by Kant RH et al. ${ }^{10}$ In the duration of menopause of 6 to 10 years, the present study had the highest incidence of atrophic endometrium, whereas study by Kant $\mathrm{RH}$ et al ${ }^{10}$ showed highest incidence of endometrial hyperplasia in this group also. In the duration of menopause more than 10 years, the present study and study by Kant RH et al10 had incidence of atrophic endometrium in maximum number of patients. Simple hyperplasia was the common finding among the types of hyperplasias in postmenopausal bleeding in the present study, which is similar to study by Kant $\mathrm{RH}$ et al.10 Medical illnesses were found more prevalent in patients with atypical hyperplasia and endometrial adenocarcinoma.

\section{CONCLUSION}

From our study, it was observed that the most common cause of postmenopausal bleeding was atrophic endometrium followed by endometrial hyperplasia. Medical illnesses were found more frequent in patients with atypical hyperplasia and endometrial adenocarcinoma as risk factors.

\section{REFERENCES}

1. Goodman A. Postmenopausal uterine bleeding. Cited 9 0ct, 2016. Available from:http:// www.update.com/ contents/postmenopausal-uterine-bleeding.

2. Dawood NS, Peter K, Ibrar F, et al. Postmenopausal bleeding: causes and risk of genital tract malignancy. J Ayub Med Coll Abbottabad 2010;22(2):117-20.

3. Tandulwadkar S, Deshmukh $\mathrm{P}$, Lodha $\mathrm{P}$, et al. Hysteroscopy in poatmenopausal bleeding. J Gynec Endosc Surg 2009;1(2):89-93.

4. Astrup K, Olivarius Nde F. Frequency of spontaneously occurring postmenopausal bleeding in the general population. Actaobstetricia et Gynecologica Scandinavica 2004;83(2):203-7.

5. Brand $\mathrm{AH}$. The women with postmenopausal bleeding. Australian Family Physician 2007;36(3):116-20.

6. Smith-Bindman R, Weiss E, Feldstein V. How thick is too thick? when endometrial thickness should prompt biopsy in postmenopausal women without vaginal bleeding. Ultrasound obstet Gynaecol 2004;24(5):558-65.

7. Feldman S. Evaluation of the endometrium for malignant and premalignant disease. Cited 9 Octb, 2016. Available from:http://www.update.com/contents/evaluation-ofthe-endometrium-for-malignant-or-premalignantdisease.

8. Kothapally K, Bhashyakarla U. Postmenopausal bleeding :clinicopathologic study in a teaching hospital of Andhra Pradesh. Int J Reprod Contracept Obstet Gynecol 2013;2(3):344-8.

9. Breijer MC, Timmermans A, Van Doorn HC, et al. Diagnostic strategies for postmenopausal bleeding. Obstetrics and Gynaecology international Article ID 850812, 2010;2010:5. 
10. Kant RH, Iqbal A, Rather SY, et al. Significance of clinical and histopathological evaluation in women with postmenopausal bleeding: a hospital based study in Kashmir. Journal of evolution of medical and dental sciences 2015;42(4):7371-80.

11. Dangal G. A study of endometrium of patients with abnormal uterine bleeding at Chitwan valley. Kathmanduuniv Med J 2003;1(2):110-2.

12. Kaur M, Singh R, Sharma M. Endovaginal sonographic evaluation of postmenopausal uterine bleeding. Journal of clinical and diagnostic research 2010;4(2):2175-82.

13. Karmarkar PJ, Wilkinson A, Rathod M. Histopathological evaluation of postmenopausal bleeding. Journal of dental and medical sciences 2014;13(10):53-7.

14. Naik VS, Rege JD, Jashnani KD. Pathology of genital tract in postmenopausal bleeding 2005 (cited 9 oct, 2016). Availablefrom:http://www.bhj.org.in/journal_2005_470 3_july/html/original_pathology_250.htm.
15. Ahmed JA. Clinicopathological evaluation of postmenopausal uterine bleeding in Mosul city. Tikrit Medical Journal 2007;13:73-8.

16. Bharani B, Phatak SR. Feasibility and yield of endometrial biopsy using suction currete device for evaluation of abnormal pre and postmenopausal bleeding. J Obstet Gynecol India 2008;58(4):322-6.

17. Yousaf S, Shaheen M, Rana T. Frequency of endometrial carcinoma in patients with postmenopausal bleeding. ANNALS 2010;16(4):290-4.

18. Gredmark T, Kvint S, Havel G, et al. Histopathological findings in women with postmenopausal bleeding. British journal of Obstetrics and Gynaecology 1995;102(2): 133-36.

19. Rani RP, Devi JK, Papa D, et al. Transvaginal sonography and progesterone challenge test for identifying endometrial pathology in postmenopausal women. J of Obs and Gyn of India 2008;52:135-8. 